\title{
SOCIAL WORKERS AND THE EVALUATION OF
}

\section{RESIDENTIAL INSTITUTIONS}

\author{
Barry Pehrsson \\ Fordham University \\ Mary Anne Pehrsson \\ Pearl River School District - New York
}

The societal definition and control of deviance originated in the Garden of Eden when "woman" preferred "the forbidden fruit" to man and celestial retribution, rejection, retaliation and rehabilitation transpired. After a few millenia the rehabilitation services that we offer our social deviants: the "criminal," the "drug addict," "P.I.N.S.," the "mentally handicapped" and the "blind" have not advanced beyond the Biblical "solution"-namely, labeling, ostracism and the imposition of stigmata. Indeed, our rehabilitative agencies are so in name only, beneath the guise of professionalism displayed in these agencies is the latent function which they, perform: they are contemporary "zoo keepers of deviance." The lessons of Attica, the insights of Menninger, 2 Mitford, 3 and Sykes 4 all question the viability and feasibility of rehabilitation with in the parameters of our existing penal or "correctional" institutions. The dominant theme running throughout the literature on penology is that our correctional institutions are "holding cages" designed for social control but not for the social rehabilitation of the inmate. Attica has sensitized us to the need for true prison reform and wardens are now finding it somewhat difficult to direct prison social systems that they themselves have come not to believe in.

Nevertheless, the purpose of this article is not to consider an analys is of institutional penal reform, a number of commissions are devoting themselves to that endeavor; hopefully their efforts will be fruitful and their insights synthesized and acted upon. What we wish to consider is the nature of a select type of social service that is being offered to one distinct marginal group in our society: institutionalized, dependent, physically-sound children. By examining some of the major modalities employed in the institutional treatment of this distinct grouping we would hope to show how once again our "best" rehabilitative efforts only reinforce and create deviance instead of reintegrating the client into the dominant social structure.

Realizing that "rehabilitation" and other social services must be analyzed within the framework of the fabric of American society and its value 
complex, it would be helpful to survey that culture complex as it exists in the urbanized, bureaucratized, industrialized, post-industrial state that characterizes the 1970's. Over fifty years ago Georg Simnel warned that

The deepest problems of modern life derive from the claim of the individual to preserve the autonomy and individuality of his existence in the face of overwhelming social forces, of historical heritage, of external culture, and of the technique of 1 ife. 5

Another classic social theorist, Max Weber also noted that an urban culture often eventuates in impersonalization as a result of its structure as a market-settlement. 6 A contemporary social theorist, Alvin Gouldner attests to the validity of the Simmel-Weber thesis when he points out that
... In large reaches of our society and particularly in
the industrial sectro, it is not the man that is wanted. It is, rather, the function he can perform and the skill with which he can perform it for which he is paid. If a man's skill is not needed, the man is not needed. If a man's function can be performed more economically by a machine, the man is replaced.7

Gouldner emphasizes that the utilitarian culture which characterizes American society forces the individual to suppress or repress vast parts of his personality in the course of playing a role in industrial society. Punctuality, calculability and exactness become the instrumental values through which modern man becomes a functionnaire. 8

It is no wonder that given the above mentioned restrictions that modern post-industrial man should suffer from a symbolic shortcoming in meaning - an identity crisis. Orrin E. Klapp has delineated the dominant common symptoms of the all pervasive identity problem. Amongst the symptoms are: a feeling of being blemished, self-hatred, oversensitivity, excessive self-concern, a feeling of alienation, a feeling of unrealized potential, a desire to be someone else, excessive consciousness of playing a "plastic role," and excessive other directedness.9 The sources which lead to this identity crisis are structural, not individual per se. American society is characterized by a future-shock technology, a knowledge explosion, mobil pluralism, lack of meaningful employment and the opportunity to prove oneself within the confines of the Protestant ethic. When one adds to this structural potpouri advertising pressures which stimulates the struggles for status symbols one is not surprised that feelings of powerlessness, anomie, marginality and al ienation characterize the American people. Given this trend towards impersonality and mass-alikeness of human relations the dominant question of the twentieth century becomes "Who am I?"

Philip Slater suggests that three human desires are deeply frustrated by American culture: The desire for community--the wish to live in trust and fraternal cooperation; the desire for engagement--the wish to come directly to grips with impersonal problems; the desire for dependence--the wish to share responsibility for the control of one's impulses and direction of one's life. Social workers express the same concept in terms of individual human needs; the need for affection, the need for security, the need for achievement, the need for acceptance in a group. As a result of the structural value complex an 
avoidance tendency has grown within the American character. Slater notes that our approach to social issues inevitably falls back on cinematic tradition in which social problems are solved by a wave of the magic wand or by gesture. Once a law is passed, a commission established, a study completed, a report concretized, the problem is expected to have been "solved." Slater calls our attention to the fact that:

\section{...The institutions we provide for those who cannot care for themselves are human garbage heaps-they result from and reinforce our tendency to avoid confronting social and interpersonal problems. 10}

Our ideas about institutionalizing the psychotic, the aged, the retarded, delinquent, criminal, blind, and infirm are based on a cultural avoidance mechanism called the Toilet Assumption. As Michael Harrington and others note our approach to social problems is to exercise them out of our consciousness by physically removing the symptom of the problem--the deviant--from our line of vision; in sum, we literally flush him away from our consciousness. 11 When our discharded problems rise to the top of our cesspools, as they did at Attica, we are shocked and disgusted. Immediately we call in a "social plumber"--a sociologist or social worker to head a commission so as to anesthetize ourselves to reality. This is the nature of our crisis mentality. Thus, our social problems are ghettoized, social conflict diminishes, disorder receded and we again attain a purified identity.12

If the "Toilet Assumption" does not function adequately then we resort to another ideological process: blaming the victim. William Ryan theorizes that "blaming the victim" is an ideological process, a set of ideas and concepts deriving from systematically motivated, but unintended distortions of reality designed to change an individual deviant and not the structural problems that cause individual problems. As Ryan notes:

And almost all our make-believe liberal programs aimed at correcting our urban problems are off target; they are designed to change the poor man or to cool him out.13

Thus, in our consumer society, a society which tends to depersonalize, manipulate, and al ienate, we pursue the dying myth of underending consumption and consume prepackaged values.14 suffering from our own structurally induced inadequacies we exist in the cuiture of silence consciously or unconsciously attempting to insulate ourselves to the social problems that surround us. It is with in this "Gestalt" of a culture of emotional poverty that our social services are conducted.

After surveying five residential treatment centers which may be characterized as "total institutions" designed to care for the physical and emotional needs of a group of children who were labeled "P.I.N.S." or "wards of the State," and who ranged in age from five to eighteen years, the authors recognized the same consistent pattern of socialization and "rehabilitation" which permeated the therapeutic milieu of each and every agency. Realizing the narrow scope of the research design, the authors are aware of the severe limitations of their statements. Nevertheless, since our observations on the nature of residential treatment agencies are in agreement with a substantial body of theoretical research on the nature of residential treatment milieus, we have chosen to 
generalize our specific findings about the major modalities of residential social services provided for children.

The unstated assumption of the accommodative philosophy that permeates the above mentioned institutions is that the majority of the clients will end up organizing their lives around the agency. The "child" has little choice but to remain a part of the environment that has been designed and engineered to accommodate him. As Bredemeier has noted the return of the client to the community does not carry with it any guarantee that he is now a "finished product" who can be socially integrated into the society. Requirements of conventional life with in the community, community performance requirements are largely ignored by the treatment and socializing agency. Bredemeier points out that:

...many agencies have been forced away from defining themselves as in the business of producing productive and responsible citizens. Many of them seem to have accepted the conception that they are warehouses for storing people until someone withdraws them, or they escape, or are otherwise conveniently gotted rid of. 15

Thus, within the residential institution the goal of maturation is distorted to mean an improvement in the degree of internalization of institutional norms. The concept of maturation which is espoused by the institution is a goal which is functional for the institution and requires long-term maintenance of the client. The definition of successful socialization is revised from a process of learning by which an individual is prepared to meet the requirements that society has set for his behavior in a variety of social situations to a process of learning survival norms for institutional culture. The agencies' socialization process seems to contradict a basic social-psychological principle:

The identity of the individual, both to himself and to others, is largely compounded of the web of symbolic communications by which he is linked to the external world; the structure of the human personality is so much a product of social interaction that when this action ceases it tends to decay. 16

In sum, the residential programs do not adequately develop a reality oriented approach to aid children to integrate into the dominant culture from a position of strength. The manifest function of rehabilitation develops into the latent function of reinforcement into a dysfunctional dependent role.

The treatment center becomes a tension-management device that thwarts the child's maturational process, prevents the development of an adequate concept of self and subsequently infantilizes him. Instead of a socialization for multiple societal adaptions the child is regimented within the institutional culture. Erik Erikson and other developmental psychologists constantly note that growth is often a process of confronting new situations and adequately coping with these situations. In the regimented institutional milieu these experiences are quite often non-existent.

The argument of the societal reaction theorists would be helpful in developing a framework for summarizing our research observations. 17 The main argument of the societal reaction theorists is that persons who have experienced a series of unfavorable societal reactions as a result of a primary deviance often aiter that deviance, internalize the negative societal reactions, and become 
secondarily deviant. The child in need of supervision, the abused child, the neglected child already suffers from primary deviance. Within the institutional nexus he is socialized for dependency, he is routinized and thereby develops a secondary deviance. In sum, we mainta in that in the residential treatment center social work counseling, psychological testing, treatment, individual ized educational programs, and other "innovative techniques" all develop out of an overriding concern for custodial care. All of these services are ancillary and an extension of the custodial institutional process. The latent function of the institution becomes socialization into a dependency situation that allows custodial personnel to maintain order, to maintain "a holding-operation."

The above research observations are not unique, indeed they follow in a long history of institutional analysis and organizational criticism. Erving Goffman, 18 David Wineman, 19 Robert Vinter 20 have all noted that residential institutions often substitute standardization for individualization and treat clients as an amorphous whole. The consequences of this process are regimentation, depersonalization, dehumanization, alienation, in a word, secondary deviance. The situation and consequences of client powerlessness and agency overcontrol were summarized in a comprehensive report on deprivation issued by the National Institute of Child Health and Development. The report notes that "...welfare and other recipients of community agencies are not only afflicted by a sense of powerlessness but also are afflicted by a sense that they have no choice but to adopt stances of abject passivity in order to survive.21 Over ten years ago the President's Panel on Disability developed an "innovative proposal" regarding residential institutions. The panel observed:

The challenge to State institutions is how to accelerate the change from large isolated facilities, to smaller units close to home of the patients and to the health, education, and social resources of the community; and the challenge to both state and private residential facilities is how to replace the old concept of cus todial care, wherever it still exists,
with modern programs of therapy, education, and research.22

The striking fact is that more than ten years after the bulk of research on residential institutions was published, nothing has substantially or intrinsically changed within institutional socialization networks. Our research findings coincide with the organizational criticism that was leveled at treatment agencies by social workers and sociologists in the early 1960's. Two questions immediately come to mind: "Why is this so?" and "What can be done?"

The seemingly logical explanation for the persistence of institutional ills would be agency size. The necessity of caring for and co-ordinating the activities of a large number of clients on a twenty-four hour basis does create pressures for routinization and regimentation. Nevertheless as Vinter points out:

...the use of standarized group management procedures is not determined simply by size, but by choice among alternative technologies. When clients are viewed as more alike than different they can conveniently be handled routinely and in the aggregate. 23

If the dominant explanation for agency philosophy does not necessarily center around size, it possibly centers around an attitudinal component reflecting two different constituencies whose "needs" the agency is meeting. 
These needs may actually be not only different but contradictory. Scott points out:

As a rule, the constituency consisting of people in the
community is a much more powerful one than the constituency
consisting of stigmatized people. The reasons for this are
that laymen, and not clients, control an institution's
financial resources, do that lay control and power are built
directly into the fabric of the program. 24

In sum, the agency is "serving" two masters, a dependent institutionalized population and the larger society. Given the parameters of the American value complex and the tendency for isolation and insulation of socjety from the dominant social problems, the anesthesia syndrome, it becomes apparent that the "problem solving" style of the agency will be a slow, reactive, and post factum one designed to serve the status quo. As Gouldner notes:
Rather than taking a lead on the target, therefore, the Welfare State commonly shoots directly at or behind it. But the ineffectuality of the Welfare State derives even more fundamentally from the fact that it must seek solutions within the framework of the master institutions that cause the problem.25

The second explanation for the persistence of the institutional structure and socialization techniques is the relative powerlessness of the social worker within the structure of the agency's bureaucratic organization. The bureaucratic structure of which the worker is a part manipulates and co-opts him in order to preserve the status quo, thus the worker is forced to struggle on behalf of his clients from a position of powerlessness which often eventuates in treating clients as objects.26 As Howard and Somers note in their essay on resisting institutional evil from within: "Unless he is careful, the spy comes in from the cold and forgets being a spy." 27 Therefore the case worker involves himself in a continued progressive therapy of symptoms which at best is merely a process of "Bandaiding" a severe wound. Given these structural restraints the question of what can be done arises.

With sufficient structural changes the residential agency can serve as a beachhead into the dominant value complex. It should provide the same type of base for security, peace and psychosocial satisfaction that the immigrant community has historically provided.28 Perhaps Talcott Parsons' general paradigm of four stages for the social control of deviant behavior can be operationalized and applied to the control of secondary deviance.29 In achieving the complete reintegration of an individual into a group which had labelled him as deviant, the client must traverse four stages: support, permissiveness, restriction of reciprocity and reward. In the first stage, support, the child is assured that he is not rejected by the "normal smiths" and that he is accepted as capable of performing a norma? role. This stage therefore helps eliminate the self-fulfilling prophecy which fosters non-deviant behavior. The second stage is permissiveness: the child is not held responsible for recurrences of secondary deviance as long as he is attempting to avoid them. The third stage is restriction of reciprocity: while recurrence of deviance is understood it is not encouraged thereby preventing the "change agent" from reinforcing the secondary deviance. The final stage is providing esteem, that is rewarding any conformity that the child manifests, conformity being defined as behavior 
which makes him less dependent on the institution and more capable of integrating into the dominant culture complex from a position of strength.

Nevertheless, as a result of our individualistic orientated value complex and our avoidance tendencies we as a society have limited the possibilities of collective action for the rehabilitation and reintegration of the "deviant." As Zald notes:

If cultural traditions place a strong emphasis on individual responsibility and action, then collecitive solutions are likely to be resisted. On the other hand, a group can have values which stress an importance of collective actions as a general rule and, consequently, welfare problems, too, will call forth a collective response. 30

Ivan Illich warns that the future depends more upon our conscious choice of institutions which support a life of action rather than on our developing new ideologies and new technologies. The solution lies not in quantification-pouring new funds into old institutions but rather we need a set of criteria which will permit us to recognize those institutions which support personal growth over addiction. 31 Illich notes that these institutions should be convivial as opposed to our existing manipulative institutions. By logical extension, our manipulative social services agencies are either socially or psychologically addictive. Social addiction consists in the tendency to prescribe increased treatment if smaller quantities do not yield the required results. Thus bigger residential institutions, bigger jails and bigger nursing homes are preferred as the panacea for our auto-anesthesia. Unfortunately, this "panacea" leads to the ritual of rising deceptions.32 If the creation of convivial institutions is the goal how can it be implemented, how can social case work methodology aid in its implementation, and finally what is the set of criteria which permits us to recognize those institutions which foster and support human growth?

Since our problems are processive in nature what is needed is a processive social work methodology and processive sociological construct as opposed to methodologies and theories which pass for the definitive statements about the social construction of reality. Social workers need a philosophical and ethical framework that provides guidelines for social work intervention. Realizing that social work neutrality (non-judgemental attitude) is a myth, the caseworker must combine efforts to help clients with efforts to change society. The social worker must be conscious of the fact that he is involved in the politics of therapy and must evaluate his role in terms of its impact on the social system. 33

Social workers must maneuver themselves into positions as agents within the agency structure at the same time as they diminish the pervasive agency insecurity which eventuates from institutional change. In sum, social workers must see that their roles as "advocates" and "enablers" are essential and that social planning and social action is imperative. 34 At the same time, caseworkers must be pragmațic about the limits of social change. What is needed in social work is a "typology of advocacy" - - advocacy must be divided into two distinct but complimentary areas. Lower level advocacy which involves "bandaiding" is essential for the "resolution" of the clients' immediate problems. Higher level advocacy which opts for social change and institutional reform is also quite essential. Social work must develop a division to realize its twin goal. 
In a society which suffers from an avoidance tendency, conscientization is necessary. Although the politics of destabilization and deinstitutionalization as advocated by radical sociologists and social workers seems praiseworthy it fails to take cognizance of the societal power structure as it exists. The social worker as a pragmatist should avoid subjecting himself and his client to a martyr role. As an advocate and enabler the social worker should be aware of the following limitations and obstacles for change:

1) collaborative strategies will result only in programs and policies which the existing power configuration deems acceptable

2) power will not be surrendered voluntarily

3) when institutional change is being attempted social workers will often find themselves co-opted and controlled.35

Although it is nice to dream about Camelot it would be cruel for social workers and sociologists to drug themselves into the belief that camelot is attainable in one grand revolutionary master plan. What is needed is many people conscientiating and sensitizing each other to the problems and processive solutions for our societal ills. Nevertheless, it is necessary to realize that even conscientization has structural and temporal limits.

As a step towards sensitization and conscientization the authors suggest the following criteria for the evaluation of existing social service agencies and for the establishment of convivial institutions. Although the questions were drawn from our experience evaluating residential child care agencies, the criteria center around two polarities: the agency and the client.

As a change-agent the social worker should ask the following questions of the agency:

A) Who are the real direct and indirect consumers of the service as provided?

B) Are innovations cloaks for the status quo and political tension-management devices?

C) How can you prevent the change-agent from inordinately threatening other professional agency personnel?

As an advocate and enabler the social worker should ask the following questions about his client:

A) How does the client view his role within the agency structure: Whe is he there and why does he think he is there?

B) In the process of "rehabilitation" or "Custodial care" within the therapeutic milieu, is the client further dehumanized and made inordinately dependent?

C) Within the agency milieu has the client been socialized for reality or has he been socialized into a dependent institutional role which he internalizes and which prevents societal integration.

In sum, uniting both areas the social worker must determine if the agency has a preoccupation with custodial care or social reintegration and what are the al ternative interpersonal networks necessary for the social reintegration of the $c l$ ient. 
In sum, we argue that social workers and sociologists should not delude themselves and the public about the true dysfunctionality of their bandaiding syndrome but rather should demand further future research for new al ternative, convivial, institutional structures. The solution is not simply more fundings being poured into existing child care agencies which perpetuate dependency and create secondary deviance. What is needed is a national conscientization of the implications of the Toilet Assumption as it applied to all marginal groupings: the "blind," the "addicted," the "criminal" and the child who becomes a "ward of the state." Forever we should keep in mind the warning of Bernard, Ottenberg and Red1:

No one, of course, could possibly retain his mental health and carry on the business of life if he remained constantly aware of, and emphatically sensitive to, all the misery and injustice that are in the world. But this very essentiality of dehumanization, as with defenses, makes for its greatest danger: that the constructive selfprotection it achieves will cross the ever-shifting boundaries of adaptivenesss and become destructive, to others as well as to the self. 36

As they develop their social intervention ethic social workers should bear in mind that social charity never replaces social justice. Realizing that the greater divider of people is insecurity and that in the twentieth century the only way social casework can prevent itself from going backwards is to go forward. Social workers and sociologists must move for the development of an ethic that avoids the quantified revolution of rising deceptions.

\section{Footnotes}

1. Jock Young, "The Zoo-Keepers of Deviancy," Catalyst V (Summer, 1970, 38-54.

2. Karl Menninger, The Crime of Punishment. New York: Viking Press, 1968.

3. Jessica Mitford, Kind and Usual Punishment. New York: Alfred A. Knopf, 1973.

4. Gresham M. Sykes and David Matza, "Techniques of Neutralization," American Sociological Review, XII (December, 1957), 664-670.

5. Kurt $H$. Wolff, The Sociology of Georg Simmel. New York: Free Press, 1950. Translated by H.H. Gerth and C. Wright Mills.

6. Max Weber, The City, New York: Free Press, 1958. Translated and edited by Don Martindale and Gertrude Newwirth.

7. Alvin Gouldner, The Coming Crisis of Western Sociology. New York: Basic Books, 1970, p. 73 .

8. Ada W. Finifter, ed., Alienation and the Social System, New York: John Wiley, 1972.

9. Orrin E. Klapp, Collective Search for Identity. New York: Holt, Rinehart and Winston, Inc., 1969, pp. 11-14. 
10. Philip Slater, The Pursuit of Loneliness. Boston: Beacon Press, 1970:5. 11. Michael Harrington, "The Welfare State and its Neo Conservative Critics," Dissent (Fall, 1973), pp. 435-454.

12. Richard Sennett, The Uses of Disorder. New York: Vintage Books, 1970, 3-49.

13. William Ryan, Blaming the Victim. New York: Pantheon Books, 1971.

14. Ivan Illich, Deschooling Society. New York: Harper and Row, 1970, pp. 49-74.

15. Harry C. Bredemeier, "The Socially Handicapped and the Agencies: A Market Analysis," in Frank Riessman, Jerome Cohen and Arthur Pearl, eds., Mental Health of the Poor. New York: Free Press, 1964, p. 107.

16. Kingsley Davis, Human Society. New York: Macmillan Co., 1949, p. 152.

17. Edwin M. Schur, Labeling Deviant Behavior: Its Sociological Implications. New York: Harper and Row, 1971. Edwin Lemert, Human Deviance, Social Problems and Social Control. Englewood Cliffs, New Jersey: Prentice Hall, 1967.

18. Erving Goffman, Asylums. Garden City, New York: Doubleday \& Co., 1961. 19. David Wineman and Adrienne James, "The Advocacy Challenge to Schools of Social Work." Social Work, XIV (April, 1969), pp. 23-32.

20. Robert Vinter, "Analysis of Treatment Organizations," Journal of Social Work, VIII (July, 1963), p. 3-15.

21. Perspectives on Human Deprivation: Biological, Psychological and Sociological (Washington: U.S. Department of Health, Education and Welfare, 1968), p. 233.

22. Lewis Mahon, A Proposed Program for National Action to Combat Disability. Washington, D.C. : United States Government Printing Office, October, 1962, p. 134 .

23. Vinter, op. cit., p. 7.

24. Robert A. Scott, "The Construction of Conceptions of Stigma by Professional Experts," in Jack D. Douglas, ed., Deviance and Respectability. New York: Basic Books, 1970, p. 274.

25. Gouldner, op. cit., p. 81 .

26. Harry Wasserman, "The Professional Social Worker in a Bureaucracy," Social Work, XVI (January, 1971), pp. 89-95.

27. Jan M. Howard and Robert H. Somers, "Resisting Institutional Evil from With in," in Nevitt Sanford and Craig Comstock, Sanctions for Evil. San Francisco: Jossey-Bass, Inc., 1971, p. 272.

28. Joseph P. Fitzpatrick, S.J., "The Importance of 'Community'", Migration Review, I (Fal1, 1966), pp. 5-12.

29. Tal cott Parsons, The Social System. New York: The Free Press, 1951, pp. $310-314$. 
30. Mayer N. Zald, Social Welfare Institutions: A Sociological Reader. New York: Wiley, 1965, p. 141.

31. Illich, op. cit., p. 76.

32. Illich, op. cit., p. 80 .

33. Seymour Halleck, The Politics of Therapy. New York: Harper and Row, 1971.

34. Gerald Shattuck and John Martin, "New Professional Work Roles and their Integration into a Social Agency Structure," Social Work, XIV (July, 1969), pp. 13-20.

35. Roland L. Warren, The Community in America, 2nd edition. New York: Rand McNally, 1973, p. 388.

36. Viola W. Bernard, Perry Ottenberg, Fritz Redl, "Dehumanization," in Sanford and Comstock, op. cit., p. 109. 